\title{
THE PERIOPERATIVE COMPARATIVE EVOLUTION OF SURGICAL STRESS MARKERS IN COLORECTAL CANCER PATIENTS BETWEEN CLASSICAL AND LAPAROSCOPIC SURGERY
}

\author{
ERIKA BIMBÓ-SZUHAI ${ }^{1}$, ADRIAN MARIUS MAGHIAR ${ }^{2}$, MIHAI BOTEA ${ }^{3}$, ANCA HUNIADI ${ }^{4}$, \\ MIRCEA ȘANDOR ${ }^{5}$, CORINA BEIUȘAN ${ }^{6}$, IULIA CODRUȚA MACOVEI ${ }^{7}$, \\ CLAUDIA TEODORA JUDEA PUSTA ${ }^{8}$
}

${ }_{1,2,3,4,5,6,7,8}$ University of Oradea

\begin{abstract}
Keywords: $\quad$ colorectal Abstract: Multiple biological parameters were proposed to evaluate the surgical stress response in cancer, laparoscopy, the early postoperative period. Granulocyte/lymphocyte (G/L) ratio may be a useful marker and surgical stress markers, widely available. Measuring some of known surgical stress related markers together with G/L ratio $C R P$, granulocyte/lymphocyte ratio we tried to confirm the superiority of laparoscopic approach and efficiency of the G/L ratio monitoring in this period. Materials and methods: 52 colorectal cancer patients who underwent elective surgery in a private clinical hospital were evaluated preoperatively and postoperatively (day 1 and day 5) for the: $T N F-\alpha$, cortisol, $C$ reactive protein $(C R P)$ and $G / L$ ratio. Results: Only CRP levels were significantly lower in the laparoscopy group in day 1 (74.07 vs 50.32, $p=0.0461)$ and day 5 (18.37 vs 7.32, $p=0.0001)$. The $G / L$ ratio showed strong correlation with CRP levels in all measurements. Conclusions: Measurement of postoperative CRP levels confirmed the reduced surgical stress of laparoscopic colectomy for colorectal cancer in our clinic.
\end{abstract}

\section{INTRODUCTION}

The intestinal tract is very sensitive to surgical stress, mainly to the patients with colorectal cancer. At the cellular level, colorectal resections cause an increase in the level of oxygen free radicals, with consecutive changes in the nuclear and mitochondrial DNA.(1) Over the years, several strategies have been emerged and they aimed the remission of the surgical stress post colorectal surgery but they also aimed some studies whose purpose was its quantification in order to predict clinical evolution. The laparoscopic approach in the colorectal cancer surgery is thus motivated by the effort to reduce the surgical stress by minimising surgical lesions. The advantages consist in reducing postoperative pains, a faster return to bowel functions and a reduced hospital stay.(2) The most important cytokines known as being involved in initiating and supporting the response to the surgical stress include: tumour necrosis factor alpha (TNF- $\alpha$ ), interleukin (IL)-1b, IL-6, IL-8 and IL-10.(6,7) The cytokines reaction intervenes in activating the body's defences to resist to infection and maintain homeostasis. Knowing the inflammatory and immunological systemic parameters, we may predict the postoperative clinical evolution. Much more, it is important to assess the perioperative stress to allow the application of preventive measures against postoperative complications. This stress marker must be easy to measure and be immediately and widely available. Another useful indicator would be monitoring of the leukocyte formula which is immediately available at low costs. Some have shown that it can reflect the severity of surgical stress more accurately than IL-6 or PCR.(10-12) The fact that the number of granulocytes increases during prolonged surgery is well known. It has been observed a relative granulocytosis after those operations, in which a compensatory lymphocytopenia appeared.(13)

Our study aims to follow the biological markers of surgical stress during the perioperative period, in patients with colorectal neoplasm in which curative surgery is performed by laparoscopy or laparotomy. Comparing the evolution of those markers already proven to be sensitive to the inflammatory response to the surgical stress, together with the ratio of granulocytes and lymphocytes $(\mathrm{G} / \mathrm{L}$ ratio) among the patients who have suffered a laparoscopic approach and a classical surgery (laparoscopy already demonstrating lower level of surgical stress), we want to demonstrate the superiority of the laparoscopic approach and the efficiency of this last parameter which is very simple to obtain during the perioperative period.

\section{MATERIALS AND METHODS}

Our clinical, cohort, prospective, observational study took place in the surgery department of Pelican Clinical Hospital Oradea during January 2015 - August 2019. The research project has been analysed and approved by the Ethics Commission of the hospital and in case of identifying an eligible patient, an informed consent was presented and signed. Of the 3175 patients admitted during this period, 61 met the inclusion criteria and did not present any exclusion criteria. 9 patients did not sign the informed consent.

The inclusion criteria: patients with histopathologically confirmed colorectal neoplasm after

'Corresponding author: Bimbó-Szuhai Erika, Str. Delavrancea, Nr. 13, Ap. 2. 410058, Oradea, România, E-mail: bszera@gmail.com, Phone: +40740 154365

Article received on 20.09.2020 and accepted for publication on 02.12 .2020 


\section{CLINICAL ASPECTS}

colonoscopy, planned curative surgical intervention.

The exclusion criteria: age: under 18 years old, pregnant patients, evidence of distant metastasis, any preexisting inflammatory bowel disease or rheumatoid arthritis, clinically evident preoperative infection. The determination of the biological markers was done according to the following scheme (table no. 1):

Table no. 1. The pattern for collecting the biological markers in study patients

\begin{tabular}{|l|l|l|l|}
\hline \multicolumn{1}{|c|}{ Marker } & Preoperative & $\begin{array}{c}\text { Postoperative } \\
\text { day l }\end{array}$ & \multicolumn{1}{c|}{$\begin{array}{c}\text { Postoperative } \\
\text { day 5 }\end{array}$} \\
\hline TNF- $\alpha$ & v & v & \\
\hline $\begin{array}{l}\text { Serum } \\
\text { Cortisol }\end{array}$ & v & v & \\
\hline CRP & v & v & v \\
\hline G/L Ratio & v & v & v \\
\hline $\begin{array}{l}\text { TNF- } \alpha=\text { tumour necrosis factor alpha; PCR (CRP) }=\text { C-Reactive } \\
\text { protein; G/L = gramlocytes / lymphocytes }\end{array}$ \\
\hline
\end{tabular}

The collection of biological samples was done on an empty stomach, by puncturing a peripheral vein. The determinations were made from venous blood, collected in a vacutainer on anticoagulant in the case of leukocyte hemogram (for $\mathrm{G} / \mathrm{L}$ ratio), respectively in the vacutainer without anticoagulant in case of the biochemical determinations (for TNF$\alpha$, cortisol CRP (PCR)). There were used the following determination methods: automatic analyser on the principle of flow cytometry with fluorescence using semiconductor LASER and hydrodynamic focusing for blood count with leukocyte formula, immunochemical method with chemiluminescence detection for TNF- $\alpha$, latex enhanced immunoturbidimetric method for CRP and with the immunochemical detection method through the electrochemiluminescence immunoassay for serum cortisol.

In addition to these laboratory determinations, the study sheet was also filled in with the following data for each patient enrolled: sex, age, place of origin, the tumour stage (Dukes classification), type of surgical intervention (classical or laparoscopic), tumour location, days of hospitalisation, days of intensive care and the appearance of the anastomotic fistula. The anastomotic fistula has been diagnosed through clinical signs of peritonitis and/or through the evidence of a free fecal fluid in the abdominal cavity or on the drainage tubes. In case of clinical suspicion or as many times as necessary, the diagnosis was confirmed by computed tomography of the abdomen and pelvis with intravenous or anorectal contrast. Depending on the type of surgery, the patients were divided in 2 groups: $\mathrm{L}$ - those who have undergone laparoscopic surgery and $\mathrm{C}$ - those who have undergone classical intervention by laparotomy.

Statistical analysis.

The continuous variables will be presented under the form of an arithmetic mean, respectively geometric mean with standard deviation in brackets, having a normal distribution (some of them after logarithmic transformation). The categorical variables will be described by the number of observations and percentages in brackets. Statistically significant differences were considered at values less than 0.05 of the null hypothesis (p). Statistical tests were performed using the MedCalc ${ }^{\circledR}$ program, 12.5.0.0 version (MedCalc ${ }^{\circledR}$ Software, Mariakerke, Belgium). The comparison of groups for the categorical variables was performed using the chi-squared test, respectively Yates' chi-squared test when it came to $2 \times 2$ tables; the continuous variables with normal distribution were performed using the Student's test for independent groups (with or without logarithmic transformation, as the case may be); the continuous variables with asymmetric distribution have been studied using Mann-Whitney test. In order to verify the correlation between biological markers, the Spearman correlation coefficient was calculated. To demonstrate the importance of biological markers in the monitoring of perioperative stress, a much larger number of cases would be needed, being highly variable parameters. A more frequent determination of biological markers during the postoperative period would help to a more accurate understanding of the pathophysiological mechanisms underlying surgical stress. There is a possibility that some patients with subclinical anastomotic fistula may have remained undiagnosed, which would result in statistical calculation errors in the groups comparison. But usually these complications are cured without treatment and have no clinical significance.

\section{RESULTS}

Out of the 52 enrolled patients, 28 patients $(53,8 \%)$ have undergone laparoscopic surgery while the rest of 24 have undergone the classical technique, by laparotomy. The basic characteristics for the two groups thus constituted, are presented in the following table: (table no. 2):

Table no. 2. The basic characteristics for the 2 batches of study

\begin{tabular}{|c|c|c|c|}
\hline Basic characteristics & $\begin{array}{c}\text { Batch C } \\
\mathrm{n}=24\end{array}$ & $\begin{array}{c}\text { Batch } L \\
n=28\end{array}$ & $\begin{array}{c}\mathbf{p} \\
\text { (statistical } \\
\text { significance) }\end{array}$ \\
\hline $\operatorname{Sex}(M / F)$ & $14 / 10$ & $22 / 6$ & 0,2023 \\
\hline $\begin{array}{l}\text { Age (years old }) \text { - arithmetic } \\
\text { mean }( \pm D S)\end{array}$ & $70,00( \pm 6,52)$ & $\begin{array}{c}66,57 \\
( \pm 15,05)\end{array}$ & 0,3059 \\
\hline Place of origin $(\mathrm{U} / \mathrm{R})$ & $10 / 14$ & $10 / 18$ & 0,8777 \\
\hline $\begin{array}{l}\text { The tumor stage (percentage \%) } \\
\text { Dukes A } \\
\text { Dukes B } \\
\text { Dukes C }\end{array}$ & $\begin{array}{c}3(12.5 \%) \\
11(45.8 \%) \\
10(41.7 \%)\end{array}$ & $\begin{array}{c}10 \\
(35.7 \%) \\
12 \\
(42.2 \%) \\
6(21.4 \%)\end{array}$ & 0,1037 \\
\hline $\begin{array}{l}\text { The tumor location } \\
\text { Ascending colon } \\
\text { Transversal colon } \\
\text { Descending colon } \\
\text { Sigmoid colon } \\
\text { Recto-Sigmoid }\end{array}$ & $\begin{array}{l}6(25.0 \%) \\
2(8.3 \%) \\
7(29.2 \%) \\
6(25.0 \%) \\
3(12.5 \%)\end{array}$ & $\begin{array}{l}8(28.6 \%) \\
8(28.6 \%) \\
2(7.1 \%) \\
4(14.3 \%) \\
6(21.4 \%)\end{array}$ & 0,1129 \\
\hline $\begin{array}{l}\text { Days of hospitalisation - } \\
\text { arithmetic mean }( \pm D S)\end{array}$ & $12,5( \pm 3,64)$ & $\begin{array}{c}8,92 \\
( \pm 2,96)\end{array}$ & 0,0003 \\
\hline Days of ICU-median (IQR) & $3,5(3-6)$ & $2,5(2-3)$ & 0,0023 \\
\hline $\begin{array}{l}\text { Anastomotic Fistula - existing } \\
\text { (percentage \%) }\end{array}$ & $10(41.66 \%)$ & $\begin{array}{c}4 \\
(14,28 \%)\end{array}$ & 0,0567 \\
\hline
\end{tabular}

The data from the above table clearly demonstrates that the two groups of study groups are comparable, they do not present significant differences in demographic characteristics (sex, age, place of origin) and in the initial clinical characteristics (the tumour stage or location). Instead, it confirms the already known advantages of laparoscopic surgery on reducing both hospital stay and the Intensive Care stay. The number of patients with postoperative complications such as anastomotic fistulas was significantly lower among the laparoscopically treated patients $(14,28 \%$ vs. $41,66 \%)$ without achieving the level of statistical significance. The determinations of the biological markers gave the following results to the 2 groups of patients (table no. 3 ): 


\section{CLINICAL ASPECTS}

Table no. 3. The values of biological markers for the 2 groups of study

\begin{tabular}{|c|c|c|c|}
\hline Biological markers & $\underset{n=24}{\text { Group C }}$ & $\underset{n=28}{\text { Group } L}$ & $\begin{array}{c}\mathrm{p} \\
\text { (statistical } \\
\text { significance) }\end{array}$ \\
\hline $\begin{array}{l}\mathrm{TNF}-\alpha \text { - geometric mean }(\mathrm{IC} 95 \%) \mathrm{pg} / \mathrm{ml} \\
\text { preoperative } \\
\text { postoperative day } 1\end{array}$ & $\begin{array}{l}12,81(10,1-16,2) \\
8,49(6,7-10,7)\end{array}$ & $\begin{array}{c}1,50(10,2-12,9) \\
7,90(7,2-8,7)\end{array}$ & $\begin{array}{l}0,4313 \\
0,5806\end{array}$ \\
\hline $\begin{array}{l}\text { Cortisol - arithmetic mean }( \pm \mathrm{DS}) \mathrm{nmol} / 1 \\
\text { preoperative } \\
\text { postoperative day } 1\end{array}$ & $\begin{array}{c}122,77( \pm 154,6) \\
126,17( \pm 176,2)\end{array}$ & $\begin{array}{l}172,27( \pm 74,76) \\
132,82( \pm 60,6)\end{array}$ & $\begin{array}{l}0,1615 \\
0,8614\end{array}$ \\
\hline $\begin{array}{l}\mathrm{CRP}-\text { mean }( \pm \mathrm{DS}) / \text { median } \mathrm{IQR} \mathrm{mg} / \mathrm{dl} \\
\text { preoperative } \\
\text { postoperative day } 1 \\
\text { postoperative day } 5\end{array}$ & $\begin{array}{c}21,71( \pm 22,8) \\
74,07( \pm 46,9) \\
18,37(12,5-70,6)\end{array}$ & $\begin{array}{c}15,49( \pm 12,9) \\
50,32( \pm 39,1) \\
7,32(5,5-11,25)\end{array}$ & $\begin{array}{l}0,2440 \\
0,0461 \\
0,0001\end{array}$ \\
\hline $\begin{array}{l}\text { G/L ratio - geometric mean }(\mathrm{IC} 95 \%) / \\
\text { arithmetic mean }( \pm \mathrm{DS}) \\
\text { preoperative } \\
\text { postoperative day } 1 \\
\text { postoperative day } 5\end{array}$ & $\begin{array}{c} \\
4,58(3,8-5,5) \\
7,86(5,7-10,8) \\
5,66( \pm 2,34)\end{array}$ & $\begin{array}{c}5,44(3,9-7,5) \\
7,22(5,5-9,6) \\
5,13( \pm 2,79)\end{array}$ & $\begin{array}{l}0,3219 \\
0,6836 \\
0,4781\end{array}$ \\
\hline
\end{tabular}

C-Reactive protein was the only biological marker that presented significant differences between the two groups of patients during the preoperative period: the postoperative increase in serum levels was lower in patients who underwent laparoscopic surgery than in patients who underwent classical intervention by laparotomy . This difference is maintained even in the 5 th postoperative day (figure no. 1).

Figure no. 1. The evolution of serum C-Reactive protein (CRP) during the preoperative period in patients of the 2 groups of study - medium values

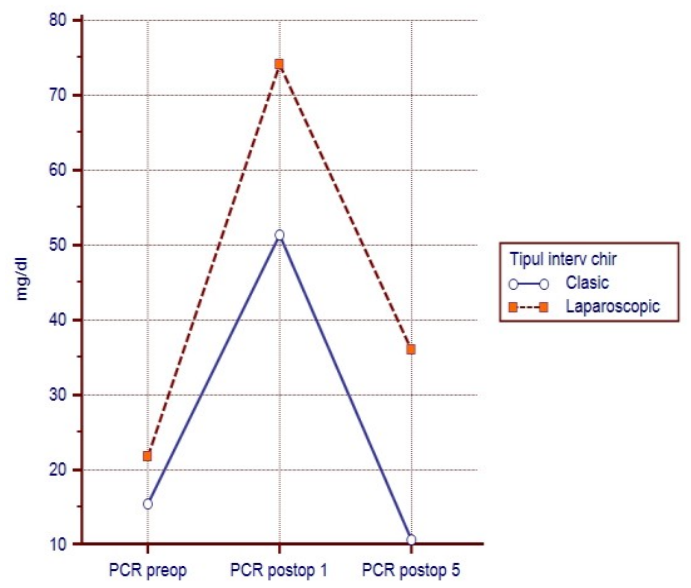

Figure no. 2. The correlation between the $\mathrm{C}$-Reactive protein (CRP) and the granulocyte / lymphocyte ratio (G/L) during the perioperative period in our study

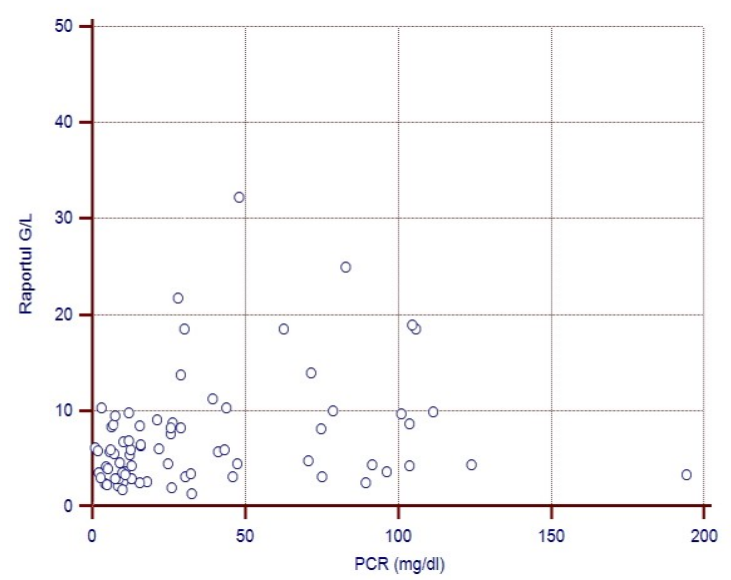

Knowing the benefits of the C-Reactive Protein in monitoring the level of operative stress and observing the results of the determinations presented in the above table, we proceed to analyse the correlation between the changes in the leukocyte formula and the perioperative evolution of C-Reactive protein, taking into account all the 156 collections of biological samples. Thus, we succeeded to demonstrate a close linear correlation between the two values with an important statistical significance (rho=0,298, $\mathrm{p}=0,0002$ ) (figure no. 2).

\section{DISCUSSIONS}

CRP, one of the most important inflammatory proteins, has been used in many studies, together with the inflammatory cytokines (IL-1, IL-6, IL-10, TNF- $\alpha$ ), as parameters for measuring the degree of surgical trauma. $(7,14)$ In this study, the group of patients who underwent laparoscopic intervention presented a lower level of CRP compared to patients with curative laparotomy. Given these data, our research suggests that laparoscopic interventions may be less traumatic than open, classical surgeries. The granulocyte / lymphocyte ratio has also been studied as an indicator of the biological response to the surgical stress.(10) Older research has already shown a significant increase in the number of leukocytes in the open cholecystectomy compared with laparoscopic cholecystectomy.(15) The surgical stress induces a profound but transient depletion of circulating lymphocytes.(16) Some studies have demonstrated that the circulating lymphocytes, during the postoperative period, are susceptible to Fas-mediated apoptosis, a possible cause postoperative lymphopenia.(17) The apoptotic index of lymphocytes was inversely proportional to the number of lymphocytes only in the immediate postoperative period and not in the following period.(17) In our study we could not demonstrate significant differences in the G/L ratio between laparoscopically operated patients compared to patients with classic interventions, but we tried to evaluate the fidelity of this indicator by correlating it with the evolution of CRP. As the result is in close correlation, we believe, however, that this ratio can help us to identify those patients with significant inflammatory response during the perioperative period. Our study confirms the already known advantages of the laparoscopic interventions of shorter hospital stay and less overall postoperative complications, advantages presented in many other studies (18-20) and gathered in meta-analyses.(21)

\section{CONCLUSIONS}

Our study suggests that determining the inflammatory response to surgical stress, by measuring the level of the CRP serum, confirms the benefits of laparoscopic surgery in the colectomy for colorectal cancer; minimally invasive method associated with clinical benefits (hospital stay, the incidence of anastomotic fistulas).

Conflict of interests:

No conflict of interests.

\section{REFERENCES}

1. Potenza L, Calcabrini C, Bellis RD, Mancini U, Polidori E, Zeppa S, et al. Effect of surgical stress on nuclear and mitochondrial DNA from healthy sections of colon and rectum of patients with colorectal cancer. J Biosci. 2011;36(2):243-2.

2. Jones OM, Lindsey I, Cunningham C. Laparoscopic colorectal surgery. BMJ 2011;343:d8029.

3. Udelsman R, Holbrook NJ. Endocrine and molecular responses to surgical stress. Curr Probl Surg. 1994;31(8):653-720

4. Jongh RFD, Vissers KC, Booij LHDJ, et al. Interleukin-6 


\section{CLINICAL ASPECTS}

and perioperative thermoregulation and HPA-axis activation. Cytokine. 2003;21:248-56.

5. Ridemann NC, Guo RF, Pete A. Novel strategies for the treatment of sepsis. Ward Nat Med. 2003;9(5):517-24.

6. Pritts $\mathrm{T}$, Hungness $\mathrm{E}$, Wang $\mathrm{Q}$, et al. Mucosal and enterocyte IL-6 production during sepsis and endotoxemia role of transcription factors and regulation by stress response. Am J Surg. 2002;183:372-83.

7. Kamińska J, Kowalska MM, Nowacki MP, Chwaliński MG, Rysińska A, Fuksiewicz M. CRP, TNF-alpha, IL-1ra, IL-6, IL-8 and IL-10 in blood serum of colorectal cancer patients. Pathol Oncol Res. 2000;6(1):38-41.

8. Wang $G$, Jiang Z, Zhao $K$, Li G, Liu F, Pan $H$, et al. Immunologic response after laparoscopic colon cancer operation within an enhanced recovery program. J Gastrointest Surg. 2012;16(7):1379-1388.

9. Nespoli L, Uggeri F, Romano F, Nespoli A, Brivo F, Fumagalli L, et al. Modulation of systemic and intestinal immune response by interleukin-2 therapy in gastrointestinal surgical oncology. Personal experience in the context of current knowledge and future perspectives. Anticancer Res. 2012;32(3):989-996.

10. Tabuchi T, Shimazaki J, Satani T, Nakachi T, Watanabe Y. The perioperative granulocyte/lymphocyte ratio is a clinically relevant marker of surgical stress in patients with colorectal cancer. Cytokine. 2011;53(2):243-248.

11. Tsimogiannis KE, Tellis CC, Tselepis AD, Pappas-Gogos GK, Tsimoyiannis EC, Basdanis G. Toll-like receptors in the inflammatory response during open and laparoscopic colectomy for colorectal cancer. Surg Endosc. 2012;26(2):330-336.

12. Tsimogiannis KE, Telis K, Tselepis A, Pappas-Gogos GK, Tsimoyiannis EC, Basdanis G. Alpha-defensin expression of inflammatory response in open and laparoscopic colectomy for colorectal cancer. World J Surg. 2011;35(8):1911-1917.

13. Lane JC, Wright S, Burch J, Kennedy RH, Jenkins JT. Early prediction of adverse events in enhanced recovery based upon the host systemic inflammatory response. Colorectal Dis. 2013;15(2):224-230.

14. Nishiguchi, K., Okuda, J., Toyoda, M. et al. Comparative evaluation of surgical stress of laparoscopic and open surgeries for colorectal carcinoma. Dis Colon Rectum. 2001;44:223-230.

15. Redmond HP, Watson RW, Houghton T, Condron C, Watson RG, Bouchier-Hayes D. Immune function in patients undergoing open vs laparoscopic cholecystectomy. Arch Surg. 1994;129:1240-6.

16. Chiarelli M, Achilli P, Tagliabue F, Brivio A, Airoldi A, Guttadauro A, Porro F, Fumagalli L. Perioperative lymphocytopenia predicts mortality and severe complications after intestinal surgery. Ann Transl Med. 2019;7(14):311.

17. Ishaque $\mathrm{A}, \mathrm{A} 1-\mathrm{Rubeai} \mathrm{M}$. Use of intracellular $\mathrm{pH}$ and annexin-V flow cytometric assays to monitor apoptosis and its suppression by bcl-2 over-expression in hybridoma cell culture. J Immunol Methods. 2018;221:43-57.

18. Veldkamp R, Kuhry E, Hop WC, et al. Laparoscopic surgery versus open surgery for colon cancer: short-term outcomes of a randomised trial. Lancet Oncol. 2005;6:47784.

19. Janson M, Lindholm E, Anderberg B, et al. Randomized trial of health-related quality of life after open and laparoscopic surgery for colon cancer. Surg Endosc. 2007;21:747-53.
20. Clinical Outcomes of Surgical Therapy Study Group. A comparison of laparoscopically assisted and open colectomy for colon cancer. N Engl J Med. 2004;350:20509.

21. Morneau M, Boulanger J, Charlebois P, Latulippe JF, Lougnarath $\mathrm{R}$, Thibault $\mathrm{C}$, Gervais N; Comité de l'Évolution des Pratiques en Oncologie. Laparoscopic versus open surgery for the treatment of colorectal cancer: a literature review and recommendations from the Comité de l'évolution des pratiques en oncologie. Can J Surg. 2013;56(5):297-310 